\title{
Contribution de Lactococcus lactis ssp lactis biovar diacetylactis au brunissement de fromages de types brie et camembert
}

\author{
M Lange ${ }^{1}$, CP Champagne ${ }^{2}$, J Goulet ${ }^{3 *}$ \\ 1 Laiterie Chalifoux, Inc, 493, bd Fiset, Sorel (Québec), Canada J3P 6J9; \\ 2 Centre de recherche et de développement sur les aliments, Agriculture Canada, \\ 3600, bd Casavant Ouest, Sainte-Hyacinthe (Québec), Canada J2S 8E3; \\ ${ }^{3}$ Département de sciences et technologie des aliments, \\ Université Laval, Sainte-Foy (Québec), Canada G1K 7P4
}

(Reçu le 18 janvier 1994; accepté le 7 mars 1994)

\begin{abstract}
Résumé - Un accident de décoloration rose-brun de fromages commerciaux de types brie et camembert a été étudié. La teneur en nitrites des fromages était inférieure à $1 \mathrm{ppm}$. La décoloration des pâtes affinées était prévenue par l'addition de sulfites, d'acide lactique ou par chauffage $\left(75-121^{\circ} \mathrm{C}\right)$, mais était accélérée par l'addition de $\mathrm{NaOH}$ en surface de la pâte. La culture mixte employée pour la fabrication commerciale comportait une proportion élevée (75\%) de Lactococcus lactis ssp lactis biovardiacetylactis. II a été possible de provoquer artificiellement le brunissement de fromages de type briecamembert, ainsi que de fromages de type bleu, en utilisant des cultures pures de $L$ diacetylactis lors de fabrications pilotes $(100 \mathrm{~L})$. Un salage prononcé $(2,1 \%)$ atténuait l'apparition de la décoloration chez les fromages affinés. De toute évidence, la décoloration était associée à la synthèse d'acétaldéhyde par le lactocoque. En modifiant la technique de fabrication du ferment afin d'y réduire la proportion de L diacetylactis et en y ajoutant une culture de Leuconostoc, il a été possible de prévenir la décoloration.
\end{abstract}

ferment lactique / acétaldéhyde / fromage / brie / camembert / Lactococcus lactis

Summary - Contribution of Lactococcus lactis ssp lactis biovar diacetylactis to the browning of Brie and Camembert-type cheeses. Pink-brown discolorations of commercial Brie and Camembert-type cheeses were investigated. Cheeses did not demonstrate high levels of nitrite, estimated at less than $1 \mathrm{ppm}$. The discoloration of the ripened cheeses was prevented by addition of sulfites, lactic acid or by heating $\left(75-121^{\circ} \mathrm{C}\right)$, but was accelerated by the addition of $\mathrm{NaOH}$ on the surface of the cheese. The mixed culture used for the commercial production showed a high proportion (75\%) of Lactococcus lactis ssp lactis biovar diacetylactis. It was possible to provoke the browning of Brie-Camembert as well as Blue-type cheeses, by using pure cultures of $\mathrm{L}$ diacetylactis in pilot-scale (100 I) production. High salting $(2.1 \%)$ reduced the intensity of discoloration in the ripened cheeses. The discoloration was

\footnotetext{
* Correspondance et tirés à part
} 
associated to the synthesis of acetaldehyde by the lactococci. By modifying the starter production method in order to reduce the $L$ diacetylactis population and by adding a Leuconostoc culture, it was possible to prevent the discoloration.

lactic starter / acetaldehyde / fromage / Brie / Camembert / Lactococcus lactis

\section{INTRODUCTION}

Un producteur de fromages de types brie et camembert a connu un accident de fabrication caractérisé par le développement d'une coloration rose-brune de la pâte, tout particulièrement lorsque les pointes de fromage affiné, fraîchement coupées, étaient exposées à l'air.

L'apparition de taches de coloration dans les fromages est généralement associée à des contaminations de surface de levures ou de moisissures (Carini et al, 1979). Une coloration complète de la pâte est toutefois beaucoup plus rare. Govindarajan et Morris (1973) ont démontré la contribution du colorant annato dans la décoloration rose de fromages cheddar. Les cultures lactiques employées en fabrication peuvent également être à l'origine de décolorations roses, et les lactobacilles semblent tout particulièrement associés à l'apparition du défaut (Shannon et al, 1969, 1977). La seule référence ayant spécifiquement trait aux décolorations roses de camembert fait intervenir les nitrites comme source de l'accident (Jacquet et Saingt, 1952).
Le but de ce travail est de déterminer quelle peut être la contribution des nitrites et des ferments lactiques au brunissement de fromages de types Brie-Camembert, et de tenter de définir l'origine de l'accident de fabrication d'un produit commercial.

\section{MATÉRIEL ET MÉTHODES}

\section{Matériel biologique}

Les ferments lactiques utilisés dans cette étude ont été fournis par l'Institut de technologie agroalimentaire (Sainte-Hyacinthe, Québec, Canada), I'Institut Rosell (Montréal, Québec, Canada) et la fromagerie commerciale qui connaissait l'accident de fabrication. Des cultures pures de Lactococcus lactis ssp lactis \#225, 270 et 145, Lactococcus lactis ssp cremoris 276, Lactococcus lactis ssp lactis biovar diacetylactis \#152 et 260 , Leuconostoc citrovorum ITA-1 ainsi que 3 cultures mixtes, C19, C26 et TUR ont été employées. Les cultures mixtes comprenaient des lactocoques et Leuconostoc dans les proportions données au tableau I.

En laboratoire, les cultures étaient maintenues dans un lait reconstitué à $11 \%(\mathrm{~m} / \mathrm{m})$ et stérilisé à $110^{\circ} \mathrm{C} / 10 \mathrm{~min}$. Trois repiquages par

Tableau I. Composition des cultures mésophiles mixtes. Composition of mixed mesophilic cultures.

\begin{tabular}{|c|c|c|c|c|}
\hline \multirow[t]{2}{*}{ Culture } & \multicolumn{3}{|c|}{ Lactococcus lactis ssp (\%) } & \multirow{2}{*}{$\begin{array}{c}\text { Leuconostoc } \\
(\%)\end{array}$} \\
\hline & lactis & cremoris & diacetylactis & \\
\hline TUR & 15 & 10 & 75 & - \\
\hline C26 & 30 & 60 & 10 & - \\
\hline C19 & 30 & 60 & 5 & 5 \\
\hline
\end{tabular}


semaine étaient réalisés en inoculant à $0,1 \%$ (v/v) et en incubant à $20^{\circ} \mathrm{C}$ pendant 16 à $18 \mathrm{~h}$. Les ferments destinés à la fabrication fromagère étaient, pour leur part, préparés dans du lait pasteurisé à $85^{\circ} \mathrm{C} / 30 \mathrm{~min}$, dans les mêmes conditions d'inoculation et d'incubation que les cultures mères du laboratoire. Leuconostoc citrovorum ITA-1, était préparée sur MRS (Difco) dans les mêmes conditions que les lactocoques.

La culture de Penicillium candidum P-9 provenait des laboratọires Roger (La-Ferté-sousJouarre, France). Elle était réhydratée dans une solution de $\mathrm{NaCl} 2 \%$.

\section{Évaluation du brunissement}

L'approche employée pour évaluer le brunissement des poudres de lait (Choi et al, 1949) a été adaptée pour nos fins. Une solution de $\mathrm{K}_{2} \mathrm{I} 10 \%$ servait de milieu de base auquel de l'iode était ajouté à des concentrations de $0,1,0,5,2$ et $5 \%$ $(\mathrm{m} / \mathrm{v})$. La densité optique $(485 \mathrm{~nm})$ de la solution de $0,1 \%$ d'iode était de 0,423 dans une cellule de $1 \mathrm{~cm}$ de diamètre installée sur un spectrophotomètre Beckman DU-7 (Irvine, CA, ÉtatsUnis). Les échantillons qui démontraient un brunissement moins élevé que le standard $0,1 \%$ d'iode étaient qualifiés de 1+. Les cotes de brunissement $2+, 3+$ et $4+$ étaient accordées aux échantillons qui se situaient respectivement dans les zones des standards d'iode 0,1 à $0,5 \%, 0,5$ à $2 \%$ et 2 à $5 \%$.

\section{Essais sur fromages de brie commerciaux}

Le brie connaissant le défaut de brunissement fut codé Com-A. Des brie de 2 autres usines, qui ne présentaient pas de défaut de brunissement, ont été codés Com-B et Com-C. Dans une première série d'essais, la croute de Penicillium était enlevée et $19 \mathrm{~g}$ de pâte étaient mélangés à $1 \mathrm{ml}$ de l'une des solutions suivantes : 1) eau distillée (témoin) ; 2) acide lactique (Fisher) $20 \%$; (3) $\mathrm{NaNO}_{2} 1 \%$; (4) $\mathrm{NaNO}_{3}$ $1 \%$; (5) $\mathrm{H}_{2} \mathrm{O}_{2} 9 \%$ et (6) $\mathrm{Na}_{2} \mathrm{SO}_{3} 1 \%$. Les mélanges étaient incubés $24 \mathrm{~h}$ à $25^{\circ} \mathrm{C}$ en aérobiose. Certains échantillons de pâte de brie ont été chauffés à $75^{\circ} \mathrm{C}$ ou $121^{\circ} \mathrm{C}$ pendant $1 \mathrm{~min}$ avant incubation.

\section{Brunissements sur substrats laitiers}

Afin d'explorer l'hypothèse qu'un des métabolites secondaires du ferment pouvait être responsable du brunissement, diverses expériences furent menées avec du lait $11 \%$ stérilisé $\left(110^{\circ} \mathrm{C} / 10 \mathrm{~min}\right)$.

Dans une première série d'essais, l'acétaldéhyde, le diacétyle ou l'acétoïne étaient ajoutés au lait à une concentration qui variait de 0 à $200 \mathrm{ppm}$. Les réactifs utilisés étaient de qualité "Baker" (JT Baker Chemicals, Phillipsburg, NJ, États-Unis) et ajoutés directement à diverses concentrations au lait après stérilisation. Les tubes contenant $20 \mathrm{ml}$ de lait étaient ajustés à $\mathrm{pH} 7$ à l'aide d'ammoniaque $4 \mathrm{~N}$ au moyen d'un titrateur automatique Radiometer TTT-80. L'examen de la culture se faisait après une incubation de 16 à $18 \mathrm{~h}$ à la température de la pièce $\left(22^{\circ} \mathrm{C}\right)$.

Dans une deuxième série d'essais, on inoculait $10 \mathrm{ml}$ de lait à un taux de $1 \%(\mathrm{v} / \mathrm{v})$ au moyen de souches lactiques sélectionnées. On incubait les tubes à $20^{\circ} \mathrm{C}$ durant $18 \mathrm{~h}$. Au terme de cette période, la surface était ensemencée de $P$ candidum P-9, et l'incubation se poursuivait alors à $7^{\circ} \mathrm{C}$ durant une période de 30 à $60 \mathrm{j}$. Ces conditions furent choisies afin de simuler celles qui sont rencontrées au cours de la fabrication, de l'affinage et de la distribution des fromages de type camembert.

Pour certains essais, nous ajoutions 5 unités internationales/ml de pénicilline (Ayerst, Montréal) au lait fermenté $(\mathrm{pH} \mathrm{4,7)}$ et inoculions alors avec $P$ candidum. D'autre part, certains laits prealablement fermentés ( $\mathrm{pH} 4,7$ ) étaient supplémentés avec $\mathrm{NaCl}$ de façon à obtenir une concentration finale pouvant atteindre $4 \%$ avant l'inoculation avec $P$ candidum. Les mélanges furent alors incubés à $7^{\circ} \mathrm{C}$ durant $60 \mathrm{j}$.

\section{Fabrications pilotes de fromages de brie et de camembert}

Les étapes de nos fabrications pilotes sont listées figure 1. Divers mélanges de ferments servirent à inoculer le lait. Le saumurage était effectué durant 30 ou 60 min à $10^{\circ} \mathrm{C}$, ce qui permettait d'obtenir des fromages ayant 1,3 ou $2,1 \%$ de sel. La pigmentation des fromages était évaluée après un affinage de $60 \mathrm{jà} 12^{\circ} \mathrm{C}$. Comme le brunissement du fromage se développait lors d'une expo- 


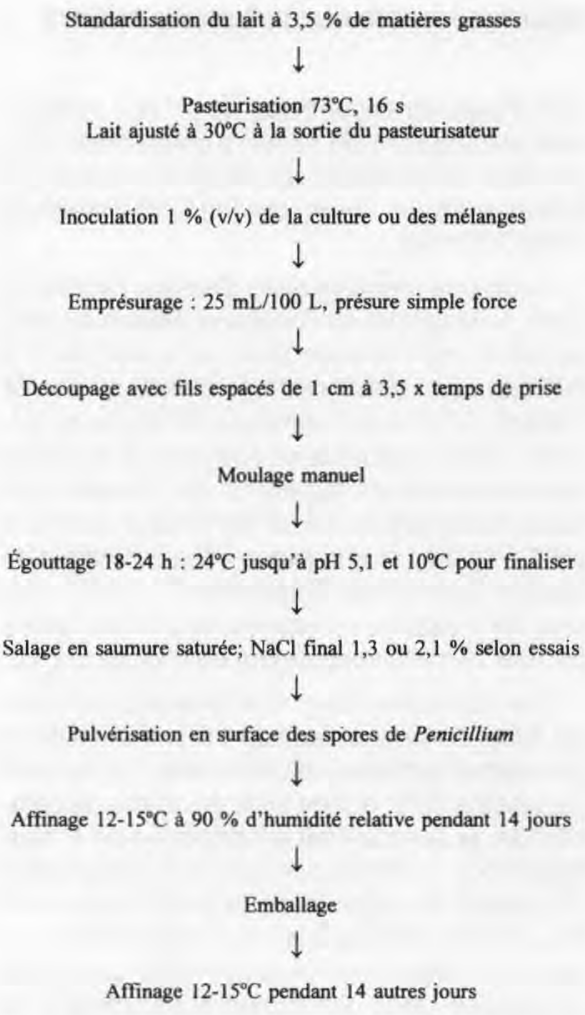

Fig 1. Méthodologie employée pour les fabrications pilotes $(100 \mathrm{~L})$ de fromage type brie.

Methodology used for the pilot scale (100 L) productions of Brie-type cheeses.

sition à l'oxygène, après avoir coupé les meules en 2, chacune des parties était conservée séparément durant $24 \mathrm{~h}$ à $10^{\circ} \mathrm{C}$, en condition aérobie.

Deux répétitions complètes et indépendantes ont été effectuées pour les essais sur substrats laitiers et les fabrications pilotes.

\section{Analyses}

Les nitrites ont été analysés selon la méthode 24.041 de l'AOAC (1980). Pour les nitrates, une résine échangeuse d'ions (forme argent) a été d'abord utilisée pour précipiter les ions chlorures et phosphates ; l'ion nitrate a été quantifié par chromatographie ionique.

La nature des flores composant les cultures mixtes a été déterminée sur le milieu de Reddy et al (1972). La population de Leuconostoc fut évaluée en énumérant les colonies démontrant un caractère hétérofermentaire, tel que révélé par une production importante de gaz dans un tube inversé (Durham) en milieu MRS.

\section{RÉSULTATS}

\section{Brunissement sur fromages de brie commerciaux}

Le brie Com-A développait une coloration rose à la surface de la pâte dans les premières heures d'exposition des tranches à l'air. Suite à une incubation de $24 \mathrm{~h}$ à $25^{\circ} \mathrm{C}$, la coloration devenait brune à un niveau 3+ (entre 0,5 et $2 \%$ d'iode). Lorsque quelques gouttes de $\mathrm{NaOH} 1 \mathrm{~N}$ étaient déposées en surface des tranches de fromage, un début de coloration rose-brun apparaissait dans les minutes qui suivaient. Par contre, l'addition d'acide lactique, de $\mathrm{H}_{2} \mathrm{O}_{2}$ ou de $\mathrm{Na}_{2} \mathrm{SO}_{3}$ prévenait l'apparition du pigment brun en $24 \mathrm{~h}$ d'incubation à $25^{\circ} \mathrm{C}$ (tableau II). Le chauffage de la pâte prévenait également le développement du brunissement. L'addition de nitrites pouvait induire le brunissement dans tous les cas. La fromagerie ComA n'ajoutait pas de nitrites ou de nitrates à son lait et l'analyse des fromages révélait une teneur inférieure à $1 \mathrm{ppm}$ en nitrites.

\section{Brunissement sur substrats laitiers}

L'apparition d'une pigmentation de couleur brune, se rapprochant de celle observée dans la pâte d'un fromage de type brie montrant le défaut, n'a pu être observée que dans les laits stériles où l'on ajoutait l'acétaldéhyde; le diacétyle et l'acétoïne ne provoquaient pas de réaction. Le brunissement 
Tableau II.Effets de divers composés et du traitement thermique sur le brunissement de fromages commerciaux de type brie.

Effect of various compounds and of the heat treatment on the browning of commercial Brie-type cheeses.

\begin{tabular}{|c|c|c|}
\hline Source & Traitement & Brunissement \\
\hline Com-A & Eau (témoin) & $3+$ \\
\hline Com-A & $\mathrm{H}_{2} \mathrm{O}_{2}$ & - \\
\hline Com-A & Acide lactique & - \\
\hline Com-A & $\mathrm{NaNO}_{2}$ & $3+$ \\
\hline Com-A & $\mathrm{NaNO}_{3}$ & $3+$ \\
\hline Com-A & $\mathrm{Na}_{2} \mathrm{SO}_{3}$ & - \\
\hline Com-A & Chauffage $75^{\circ} \mathrm{C} / 1 \mathrm{~min}$ & - \\
\hline Com-A & Chauffage $121^{\circ} \mathrm{C} / 1 \mathrm{~min}$ & - \\
\hline Com-B & Eau (témoin) & - \\
\hline Com-B & $\mathrm{NaNO}_{2}$ & $2+$ \\
\hline Com-B & $\mathrm{NaNO}_{3}$ & - \\
\hline Com-C & Eau (témoin) & - \\
\hline Com-C & $\mathrm{NaNO}_{2}$ & $2+$ \\
\hline Com-C & $\mathrm{NaNO}_{3}$ & - \\
\hline
\end{tabular}

était proportionnel à la teneur en acétaldéhyde, et atteignait 4+ suite à une addition de 200 ppm d'acétaldéhyde. II n'a pas été possible de reproduire une telle coloration du milieu à partir d'un ultrafiltrat de lait écrémé (sérum déprotéiné), ce qui suggère que la réaction de brunissement implique la participation de la fraction protéique du lait. Mohammed et al (1949) rapportent d'ailleurs des réactions de brunissement impliquant l'acétaldéhyde et les protéines. La teneur en acétaldéhyde des cultures de $24 \mathrm{~h}$ de $L$ diacetylactis et des ferments mixtes TUR et C-19 étaient de 10,3, 9,4 et 6,3 ppm respectivement.

Aucun brunissement ne s'observait dans les laits uniquement inoculés avec les cultures lactiques, en absence de flore fongique pure. La présence de $P$ candidum était donc nécessaire à l'apparition de brunissements (tableau III). Cependant, la moisissure à elle seule ne provoquait pas un brunissement marqué. En présence de Penicillium, les laits fermentés contenant
Tableau III. Effets de la culture lactique et de Penicillium candidum sur le brunissement d'un lait à $11 \%$.

Effects of the lactic culture and Penicillium candidum on the browning of milk $111 \%$ non-fat solids).

$\begin{array}{ccc}\text { Culture } & \begin{array}{c}\text { Inoculation } \\ \text { avec }\end{array} & \begin{array}{c}\text { Intensité } \\ \text { Penicillium } \\ \text { candidum }\end{array}\end{array}$

Lait stérile (témoin)

Lait stérile (témoin)

L lactis 270

L lactis 270

L lactis 145

L lactis 145

L lactis 225

$L$ lactis 225

L cremoris 276

L cremoris 276

L diacetylactis 152

L diacetylactis 152

Mixte TUR

Mixte TUR

Mixte C-19

Mixte C-19

Mixte C-26

Mixte C-26

L diacetylactis démontraient les brunissements les plus marqués.

L'addition de $0,5 \%$ de $\mathrm{NaCl}$ au lait fermenté n'a pas influencé le développement du brunissement au cours de l'entreposage (tableau IV). Cependant, l'addition de 3,5\% $(\mathrm{m} / \mathrm{m})$ de $\mathrm{NaCl}$ ralentissait l'évolution du brunissement, mais celui-ci était tout de même notable dans les échantillons ayant une forte population en $L$ diacetylactis (tableau IV). Rappelons que la culture mixte TUR provenait de l'entreprise (Com-A) dont les fromages connaissaient l'accident. L'addition de pénicilline au lait fermenté prévenait l'action des cultures bactériennes, et l'apparence des échantillons préfermentés était semblable à celui du lait stérile inoculé avec $P$ candidum (tableau IV). 
Tableau IV. Influence de l'addition de pénicilline ou de $\mathrm{NaCl}$ au lait fermenté, sur le développement du brunissement au cours de l'incubation de $30 \mathrm{j}$ à $7^{\circ} \mathrm{C}$ (avec croissance en surface de Penicillium candidum).

Influence of the addition of penicillin or $\mathrm{NaCl}$ to a fermented milk, on the development of browning during a 30 day incubation at $70 C$ (with surface growth of $\mathrm{P}$ candidum).

Culture

Traitement

Témoin $\quad 0,5 \% \mathrm{NaCl}^{1} \quad 3,5 \% \mathrm{NaCl} \quad$ Pénicilline

\begin{tabular}{|c|c|c|c|c|}
\hline Lait non fermenté & $1+$ & $1+$ & $1+$ & $1+$ \\
\hline L diacetylactis 152 & $4+$ & $4+$ & $2+$ & $1+$ \\
\hline Mixte TÚR & $3+$ & $3+$ & $2+$ & $1+$ \\
\hline Mixte C-19 & $2+$ & $2+$ & $1+$ & $1+$ \\
\hline Mixte C-26 & $2+$ & $2+$ & $1+$ & $1+$ \\
\hline
\end{tabular}

1 Comme le substrat de base contenait $11 \%$ de solides, l'addition de $0,5 \%$ de $\mathrm{NaCl}$ génère une teneur en sel dans la phase aqueuse de $0,56 \%$, tandis que l'ajout de $3,5 \%(\mathrm{~m} / \mathrm{m})$ de $\mathrm{NaCl}$ résulte en une teneur correspondante de $3,9 \%$ dans la phase aqueuse.

Ainsi, les éléments qui inhibaient les cultures lactiques au cours de l'entreposage prévenaient le développement d'un brunissement intense.

\section{Fabrications pilotes de fromages type brie}

Tout comme dans les essais en tubes, la présence de $L$ diacetylactis 152 accentue l'apparition du défaut (tableau V). Le salage du fromage à $2,1 \%(\mathrm{~m} / \mathrm{m})$ résulte en une teneur de sel dans la phase aqueuse de $3,9 \%$, identique à celle obtenue dans les études en tubes ayant $3,5 \%(\mathrm{~m} / \mathrm{m})$ de sel (tableau IV). Dans les 2 cas, le salage élevé ne prévenait pas l'apparition du brunissement, mais en atténuait fortement l'apparition. L'inoculation avec Leuconostoc citrovorum ITA-1 réduisait également le brunissement qui se manifestait lorsque les pointes de fromage ayant $60 \mathrm{j}$ d'affinage et conservation étaient exposées à l'air.
La teneur en nitrites des fromages n'a jamais dépassé 1 ppm, tandis qu'on retrouvait $110 \mathrm{ppm}$ de nitrates dans les fromages.

\section{DISCUSSION}

Le brunissement du fromage brie exposé à l'air n'est pas un phénomène normal et seuls les produits de la fromagerie Com-A présentaient cet accident. Néanmoins, tous les fromages brie ont la capacité de brunir si certaines conditions sont remplies comme en font foi les essais avec addition de nitrites (tableau II). Les nitrites ont été exclus comme étant la source du problème faisant l'objet de cette étude puisque les analyses n'ont pas révélé de teneurs notables de ce composé dans les fromages.

Outre les nitrites, la cause la plus commune de décoloration rose-brun dans les fromages est associée à certaines souches de lactobacilles (Shannon et al, 1969). Comme la culture mixte employée dans la 
Tableau V. Effet de la composition du ferment et de la teneur en $\mathrm{NaCl}$ sur le brunissement de fromages type brie fabriqués à l'échelle pilote.

Effect of starter composition and $\mathrm{NaCl}$ content on the browning of pilot-scale Brie-type cheeses.

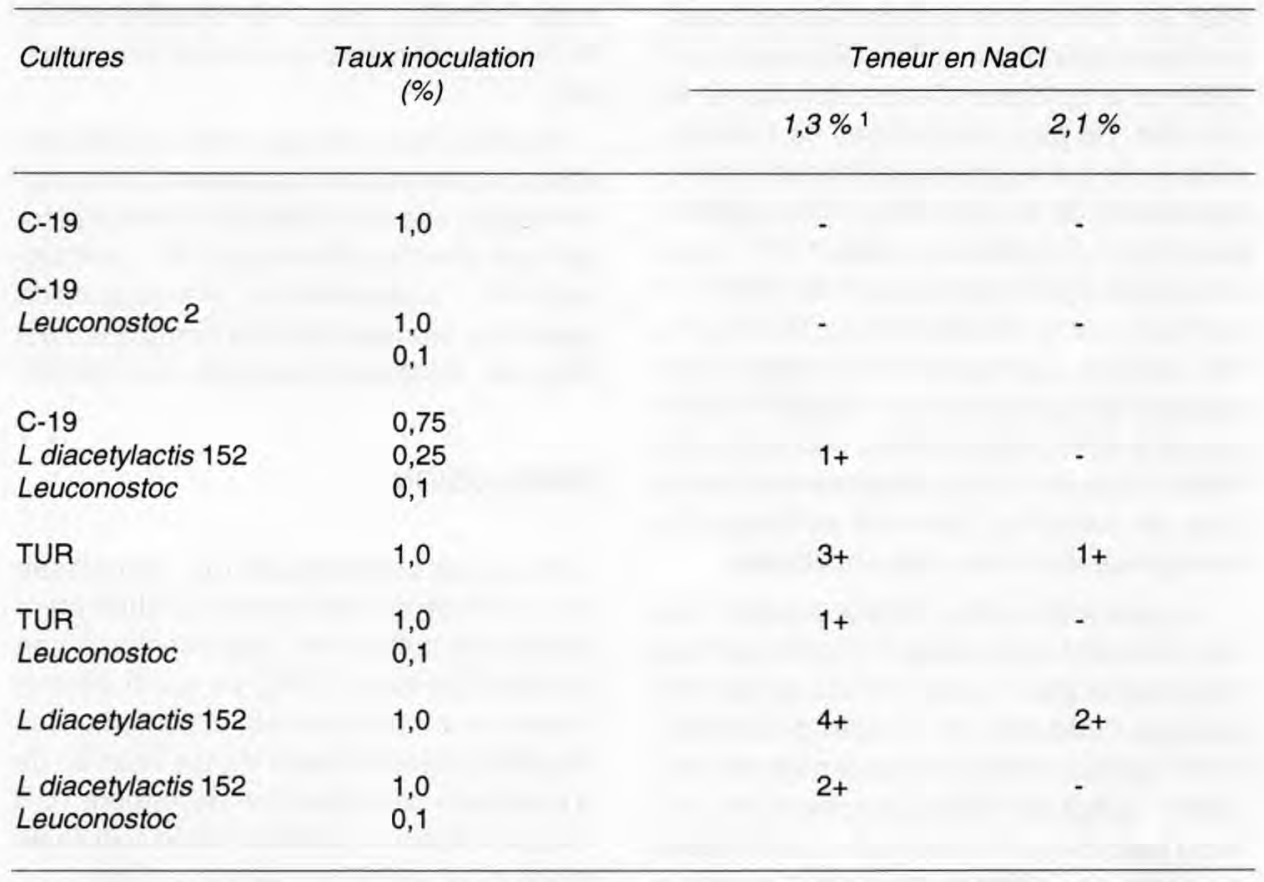

1 Sel dans la phase aqueuse de 2,4 et 3,9\% respectivement. ${ }^{2}$ Leuconostoc citrovorum ITA-1.

fabrication du fromage brie ne contenait pas de lactobacilles, nos travaux se sont donc orientés vers l'action des lactocoques. Avec du lait à $11 \%$ en tubes, le brunissement était nettement associé à la présence de $L$ diacetylactis (cultures type D). Ces souches se distinguent des autres lactocoques par leur capacité à fermenter le citrate et à produire des métabolites secondaires. Des 3 métabolites secondaires testés (acétaldéhyde, acétoïne, diacétyle), seul l'acétaldéhyde provoquait un brunissement du lait in vitro. Quatre éléments supportent l'hypothèse que l'acétaldéhyde contribue au brunissement du fromage. Tout d'abord, l'absence de brunissement suite au traitement thermique (tableau II) serait associée à une volatilisation de l'acétaldéhyde dont le point d'ébullition est de $21^{\circ} \mathrm{C}$. En second lieu, les sulfites ont la caractéristique de se combiner à l'acétaldéhyde (Amerine et al, 1980 ) et l'addition de $\mathrm{Na}_{2} \mathrm{SO}_{3}$ prévient le brunissement (tableau II). Troisièmement, la réaction de l'acétaldéhyde avec les acides aminés est favorisée par des conditions alcalines (Lea et Hannan, 1949 ; Underwood et al, 1959), ce qui expliquerait l'action répressive de l'acide lactique sur le brunissement (tableau II), ainsi que l'effet accélérateur de l'addition de $\mathrm{NaOH}$ à la surface du fromage. Finalement, l'addition de cultures de Leuconostoc, qui métabolisent l'acétaldéhyde (Keenan et al, 1966), diminue l'intensité du brunissement. 
Le phénomène que nous observons est très similaire à celui qui touche les fromages de type italien avec les lactobacilles. En effet, les cultures de lactobacilles en cause tendaient à réduire le milieu (Shannon et al, 1969 ) et la synthèse d'acétaldéhyde aurait cet effet. De plus, les cultures de Lactobacillus lactis qui ne provoquaient pas le développement de la coloration rose synthétisaient du $\mathrm{H}_{2} \mathrm{O}_{2}$ (Shannon et al, 1977); nous observons également une activité inhibitrice du $\mathrm{H}_{2} \mathrm{O}_{2}$ sur le brunissement (tableau II). Par ailleurs, Lactobacillus bulgaricus est capable de synthétiser l'acétaldéhyde en concentrations appréciables (Accolas et al, 1980). L'accident de brunissement du brie et ceux de coloration rose des fromages italiens présentent donc des similitudes.

La quantité d'acétaldéhyde produite lors de la fermentation initiale (10 ppm) semble insuffisante pour générer le brunissement, puisque l'addition de $10 \mathrm{ppm}$ d'acétaldéhyde à un lait stérile n'a pas généré de coloration. Le fait que le brunissement soit prévenu lorsqu'il y a inhibition de $L$ diacetylactis au cours de l'affinage, par $\mathrm{NaCl}$ ou par la pénicilline (tableau IV), confirme la nécessité de synthèse poursuivie d'acétaldéhyde au cours de l'affinage.

Cette synthèse d'acétaldéhyde en cours d'affinage peut s'effectuer à partir de divers substrats, dont le citrate, les acides aminés et les nucléotides (Lees et Jago, 1976, 1978). Seuls les laits fermentés auxquels on avait inoculé Penicillium ont connu un brunissement (tableau III), ce qui suggère aussi un rôle de la culture fongique dans le brunissement. II pourrait se limiter à la désacidification du milieu et à la protéolyse. Reste à déterminer si à cela peut aussi s'ajouter la synthèse de citrate ou d'autres substrats pouvant être convertis en acétaldéhyde par les enzymes de lactocoques. À ce titre, la seule présence des activités enzymatiques pourrait être suffisante, puisque la synthèse d'arômes volatils par les lactocoques n'exige pas nécessairement que ces dernières soient viables dans le produit fini (Lowrie et Lawrence, 1972). La relation entre les activités des lactocoques et de Penicillium dans le développement du brunissement mérite une étude plus poussée.

Notons finalement qu'il nous a été possible de provoquer l'apparition de la pigmentation rose-brun dans un fromage bleu, fabriqué avec la culture pure de $L$ diacetylactis 152. Le potentiel de $L$ diacetylactis de générer le brunissement de fromages n'est donc pas limité aux types brie-camembert.

\section{CONCLUSION}

L'entreprise commerciale qui connaissait ce problème de fabrication a initialement ajouté une culture de Leuconostoc à son ferment habituel (TUR), ce qui a permis d'atténuer le brunissement et confirmait les résultats pilotes (tableau V). Un examen de la procédure de préparation du ferment TUR révélait une suracidification de la culture en raison d'un refroidissement inadéquat, ce qui déséquilibrait la flore en faveur de $L$ diacetylactis. Suite à l'installation d'un système de réfrigération adéquat sur la cuve à ferment, l'équilibre de la flore a repris une dominance en $L$ lactis subsp cremoris, et le phénomène de brunissement ne s'est plus manifesté. Ce travail met donc en évidence la très grande importance de la régie des ferments en usine. Plusieurs accidents de fabrication peuvent être associés à des erreurs dans la préparation des ferments (Champagne et al, 1992), et la vigilance est de mise dans l'application des procédures de préparation des cultures servant à inoculer le lait de fromagerie.

\section{REMERCIEMENTS}

Nous désirons exprimer notre reconnaissance à D Gagné, J Boulanger, JJ Turgeon, Y Lambert et $C$ Perron pour leur support technique. 
Le ministère de l'Agriculture, des Pêcheries et de l'Alimentation du Québec (MAPAQ) a financé cette étude, dans le cadre de la thèse $\mathrm{Ph} \mathrm{D}$ de $\mathrm{M}$ Lange.

\section{RÉFÉRENCES}

Accolas JP, Hemme D, Desmazeaud MJ, Vassal L, Bouillanne C, Veaux M (1980) Les levains lactiques thermophiles : propriétés et comportement en technologie laitière. Lait 60 , 487-524

Amerine MA, Berg HW, Kunkee RE, Ough CS, Singleton VL, Webb AD (1980) The technology of wine making, $4^{e}$ edn. AVI Publishing Co, Inc, Westport, Conn, USA

AOAC (Association of Official Analytical Chemists) (1980) Official methods of analysis, $13 e$ edn. S Williams, Ed, Arlington, Virginia

Carini S, Lodi R, Giussani G (1979) La colorazione rosa nel formaggio Fontina. Latte 4, 914-920

Champagne CP, Lange M, Blais A, Goulet J (1992) Factors other than bacteriophage that affect lactic starter activity. Food Res Int 25, 309-316

Choi RP, Koncus AF, O'Malley CM, Fairbanks BW (1949) A proposed method for the determination of color in dry products of milk. J Dainy Sci 32, 580-586

Govindarajan S, Morris HA (1973) Pink discoloration in cheddar cheese. J Food Sci 38, 675678

Jacquet J, Saingt O (1952) Étude sur des fabrications accidentelles de camemberts rouges. Lait 32, 129-144

Keenan TW, Lindsay RC, Day EA (1966) Acetaldehyde utilization by Leuconostoc species. Appl Microbiol 14, 802-806
Lea CH, Hannan RS (1949) Studies of the reaction between proteins and reducing sugars in the dry state. I. The effect of activity of water, $\mathrm{pH}$ and temperature on the primary reaction between casein and glucose. Biochim Biophys Acta 3, 313-319

Lees GJ, Jago GR (1976) Acetaldehyde: an intermediate in the formation of ethanol from glucose by lactic acid bacteria. J Dairy Res 43 , 63-73

Lees GJ, Jago GR (1978) Role of acetaldehyde in metabolism: a review. 2- The metabolism of acetaldehyde in cultured dairy products. J Dairy Sci61, 1216-1224

Lowrie RJ, Lawrence RC (1972) Cheddar cheese flavour. IV. A new hypothesis to account for the development of bitterness. NZJ Dairy Sci Technol 7, 51-53

Mohammed A, Olcott HS, Conrat HE (1949) The reaction of proteins with acetaldehyde. Arch Biochem Biophys 24, 270-280

Reddy MS, Vedamuthu ER, Reinbold GW (1972) Agar medium for differential enumeration of lactic streptococci. Appl Microbiol 24, 947 952

Shannon EL, Olson NF, Von Elbe JG (1969) Effect of lactic starter culture on pink discoloration and oxidation reduction potential in Italian cheese. J Dairy Sci 52, 1557-1561

Shannon EL, Olson NF, Deibel RH (1977) Oxidative metabolism of lactic acid bacteria associated with pink discoloration in Italian cheese. J Dairy Sci 60, 1693-1697

Underwood JC, Lento HG, Willits CO (1959) Browning of sugar solutions. 3 . Effect of $\mathrm{pH}$ on the color produced in dilute glucose solutions containing amino acids with the amino group in the different positions in the molecule. Food Res 24, 181-188 